\title{
Industry Collaboration and Primary Guest Authorship of High-Impact Clinical Trials
}

\author{
Nitin Roper, $M D^{7}$ and Deborah Korenstein, $M D^{2}$ \\ ${ }^{1}$ Weil Cornell Medical College, New York, NY, USA; ${ }^{2}$ Department of Medicine, Memorial Sloan Kettering Cancer Center, New York, NY, USA.
}

J Gen Intern Med 31(1):12

DOI: $10.1007 / \mathrm{s} 11606-015-3402-7$

(c) Society of General Internal Medicine 2015

$\mathrm{T}_{\mathrm{w}}$ he Authors' Reply-

We thank Drs. Marchington and Hamilton and Mr. Gertel for their letter in response to our paper. They note that our study may not be fully comparable to previous studies on guest authorship ${ }^{1-3}$ because we did not include "revising the manuscript critically for important intellectual content" as part of our definition of guest authorship.

We agree that our study is not entirely comparable with other studies in the literature. However, the aim of our study was different than that of previous studies. We set out not just to determine the overall prevalence of guest authorship (which includes all authors) as was performed in previous studies, but to determine whether primary guest authorship (only first and last authors) was more common in trials with industry collaboration in the design, analysis, or reporting of results than among other trials.

We chose to study only primary authors given the prominent role that primary (first and last) authors have in clinical trials - generally as principal investigators - and past evidence of guest authorship primarily among first authors ${ }^{4}$. Given that no previous study, guidance, journal or publisher, to our knowledge, has defined specific authorship criteria for primary authors, we developed a definition based on International Committee of Medical Journal Editors (ICMJE) criteria that best represents the role of the primary authors in a clinical trial, which we believe includes "drafting of the manuscript."
It is certainly reasonable for Marchington and colleagues to disagree with this definition, but it is important to note that our definition was chosen a priori and was applied equally to all three groups studied: trials with industry funding with collaboration, trials with only industry funding and trials with neither industry funding nor collaboration.

Our main conclusion was that primary guest authorship was generally uncommon, but significantly more prevalent among trials with industry funding with collaboration. We believe these results are novel and important for the medical and publishing community, although they may not be directly comparable to previous guest authorship studies.

Corresponding Author: Nitin Roper, MD; Weil Cornell Medical College, New York, NY, USA (e-mail: nitinroper@gmail.com).

\section{REFERENCES}

1. Wislar JS, Flanagin A, Fontanarosa PB, Deangelis CD. Honorary and ghost authorship in high impact biomedical journals: a cross sectional survey. BMJ. 2011;343:d6128. Available at: http://www.pubmedcentral. nih.gov/articlerender.fcgi?artid=3202014\&tool=pmcentrez\&rendertype =abstract. Accessed May 28, 2014.

2. Mowatt G, Shirran L, Grimshaw JM, et al. Prevalence of honorary and ghost authorship in Cochrane reviews. JAMA. 2002;287(21):2769-71. Available at: http://www.ncbi.nlm.nih.gov/pubmed/12038907. Accessed May 27, 2014.

3. Flanagin A, Carey LA, Fontanarosa PB, et al. Prevalence of articles with honorary authors and ghost authors in peer-reviewed medical journals. JAMA. 1998;280(3):222-4. Available at: http://www.ncbi.nlm.nih.gov/ pubmed/9676661. Accessed May 27, 2014.

4. Ross JS, Hill KP, Egilman DS, Krumholz HM. Guest authorship and ghostwriting in publications related to rofecoxib: a case study of industry documents from rofecoxib litigation. JAMA. 2008;299(15):1800-12. doi:10. 1001/jama.299.15.1800. 